\section{X-Ray Mass Determination in Cells by Scanning}

IN 1949-50 Engström and Lindström published a method for determining the cell mass by means of absorption measurements in soft $\mathrm{X}$-radiation. In the wave-length range 6-12 A., the absorption of the $\mathrm{X}$-radiation is proportional to the mass of carbon, nitrogen and oxygen substances. The cells are photographed together with a reference system in which the absorption - wave-length relationship is the same. The photographic emulsion and process are the main limit to accuracy and resolving power.

The photographic process can be evaded by scanning the section of the cell with a very thin pencil of $\mathrm{X}$-rays, and then measuring the transmission direct. The possibilities of obtaining a measurable amount of X-radiation through a small stop of $1 \cdot 8 \mu$ has first been examined. The wave-lengths must be within the limits 6-12 A., and to prevent getting too great a geometrical unsharpness the pencil of rays must be almost parallel.

A sealed-off X-ray tube has been constructed which has a thin window through which the rays pass. The window is of aluminium foil $9 \mu$ thick, which at the same time serves as a filter. 'The diameter of the focus is $1.5 \mathrm{~mm}$. and the focus-window distance is $70 \mathrm{~mm}$. The anode voltage is $3 \mathrm{kV}$. and the anode current 1 m.amp. A gold micro-stop is placed immediately in front of the window. The rays pass through the stop and enter a windowless proportional counter through which methane is flowing.

The possibility of obtaining measurable quantities of rays through the micro-stop is a problem of intensity; but it is further complicated by the natural radiation giving a background, the irregular variations of which can be expected to be greater than the radiation passing through the micro-stop. This problem has been solved in the following way. The height of impulses from the proportional tube depends on the energy of the radiation. The soft, low-energy radiation which is used here gives very

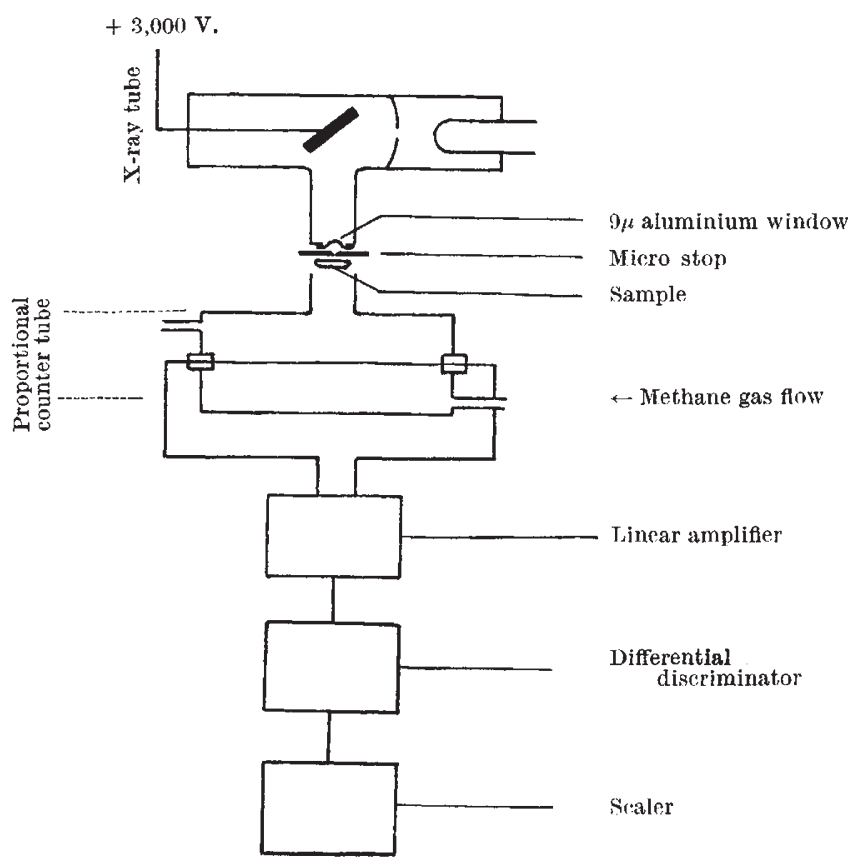

much smaller impulses than the high-energy natural radiation. The high impulses are blocked in a differential discriminator, and only impulses below a certain height reach the impulse counter. Consequently, the disturbing background becomes insignificant. By using this form of X-ray tube and these conditions of operation (Fig. 1), a micro-stop with a diameter of $1.8 \mu$ resulted in a mean of 145 impulses/min. being obtained; the background was found to be 15 impulses/min. Quite measurable quantities were thus passing the stop.

Proportional tubes in connexion with the differential discriminator, however, give still another possibility. Impulses below a certain level can also be excluded, and thus only impulses between two levels will be counted. If these levels are set close to each other, it will be possible to measure within a very narrow range of wave-lengths. This means that absorption measurements in cells of various substances can be carried out at their maximum absorption. Further quantitative examination of the chemical components in the cells should thus be possible.

Preliminary investigations have shown that mass determination in cells is possible by scanning with $\mathrm{X}$-rays. Further investigations will be published later on.

Bengt H. O. Rosengren

King Crustaf V Jubilee Clinic for Radiotherapy, University of Gothenburg. March 23.

\section{Some New Stereochemical Arrangements of Divalent Palladium and Platinum}

THe usual stereochemistry of divalent palladium and platinum is that of a square-planar arrangement, associated with $(n-1) d n s n p^{2}$ bonding. A number of structures of this type have been reported ${ }^{1}$. The stereochemistry of square complexes has been discussed in considerable detail by Mellor ${ }^{2}$. With the exception of a few compounds such as the pyrromethene $^{3}$ and triaminotrimethylamine ${ }^{4}$ complexes, where the bonds must be forced out of a plane, the four bonds to a bivalent platinum atom are invariably planar.

A few compounds have been reported in which the divalent platinum atom has been said to be six-covalent. For example, bis(acetonitrile) tetrammine platinous chloride, $\left[\mathrm{Pt}\left(\mathrm{NH}_{3}\right)_{4}\left(\mathrm{CH}_{3} \mathrm{CN}\right)_{2}\right] \mathrm{Cl}_{2}$, has been prepared in what are claimed to be cis-and trans-forms ${ }^{5}$. An octahedral arrangement has also been suggested for the bis( $\alpha, \beta, \gamma$-triaminopropane) platinous ion ${ }^{8}$. 'The evidence for the proposed octahedral arrangements is, however, purely chemical.

While investigating recently the complexes of the chelate group o-phenylenebis(dimethyl$\operatorname{arsin} \theta$ ) (denotod by diarsine) the reaction

$\left[M(\text { diarsine })_{2}\right]^{++}+X^{-} \rightarrow\left[M(\text { diarsine })_{2} X\right]^{+}$

where $X=\mathrm{Cl}, \mathrm{Br}$ and $\mathrm{I}$, and $M=\mathrm{Pd}$ and $\mathrm{Ni}$, was observed to occur in non-aqueous ionizing solvents such as nitrobenzene, and complexes of the general formula $\left[\mathrm{M}\right.$ (diarsine ${ }_{2} \mathrm{X}^{+}{ }^{+} \mathrm{ClO}_{4}{ }^{-}$ ( $M=\mathrm{Pd}$ and $\mathrm{Ni}$ ) have been isolated from acetone solutions'. These metals apparently exist as five-covalent ions $\left[M(\text { diarsine })_{2} X\right]^{+}$in nitrobenzene solution $^{2}$, for the perchlorates function as uni-univalent electrolytes in this solvent. It is to be expected that compounds 